\title{
Recent Studies in Functional Analytic Psychotherapy
}

\author{
Rafael Ferro García
}

\begin{abstract}
Functional Analytic Psychotherapy (FAP), based on the principles of radical behaviorism, emphasizes the impact of eventualities that occur during therapeutic sessions, the therapist-client interaction context, functional equivalence between environments, natural reinforcement and shaping by the therapist. This paper reviews recent studies of FAP from the published literature and classifies them into different categories, i.e., 1) integration with other therapies, 2) supervision and improvement of therapeutic skills, 3) methods for evaluation and data recording in therapy, 4) effectiveness and efficacy, 5) the relationship between thoughts and emotions, and 6) application to clinical problems and new types of application.

Keywords: Functional analytic psychotherapy, Applications, Efficacy, Effectiveness
\end{abstract}

This article reviews recent studies that have appeared since the publication of Kohlenberg and Tsai's manual on Functional Analytic Psychotherapy (FAP) (Kohlenberg \& Tsai, 1991). To date the manual has been translated into Portuguese, Japanese and Spanish, and a second edition is in preparation. Functional Analytic Psychotherapy forms part of what Hayes (2004) and O'Donohue (1998) have termed third-generation behavioral therapy, a group that includes Acceptance and Commitment Therapy (Hayes, Strosahl \& Wilson, 1999), Behavioral Activation (Martell, Addis, \& Jacobson, 2001) and Dialectic Behavior Therapy (Linehan, 1993).

As proposed by Kohlenberg and Tsai (1991, 1995a), FAP is an alternative to behavioral therapy that is based on principles of radical behaviorism, and which emphasizes the impact of contingencies arising during therapeutic sessions, the therapist-client interaction context, functional equivalence between environments, natural reinforcement and shaping by the therapist. Because the principle objective of FAP is a functional analysis of the client's behavior, it emphasizes the importance of what the client does and says during therapeutic sessions - the client's clinically relevant behaviors (CRB). Therapeutic interventions are developed from five rules of therapy in FAP (Kohlenberg \& Tsai, 1991, 1994a, 1994b, 1995a).

Functional Analytic Psychotherapy is a type of therapy that can be used alone, or that can be integrated with any other type of therapy to obtain synergistic results (Kohlenberg, Tsai, Ferro, Valero, Fernández Parra, \& Virués, 2005). Some examples below will illustrate how integration of FAP with other therapies has yielded good results. As Pérez Álvarez (2004) has explained, the main contribution of FAP to psychotherapy is that it turns the therapist-client relationship into a truly therapeutic relationship. Another contribution of FAP is the theory regarding formation of the self, which accounts for the appearance of personality disorders and suggests how they might be treated (Kohlenberg \& Tsai, 1991, 1995b).

On the basis of their main objectives I have grouped the studies reviewed here into six different and not necessarily mutually exclusive areas of research. These areas are 1) integration with other psychotherapies, 2) supervision and improvement of therapeutic skills, 3) new developments in methods for evaluation and data recording, 4) studies of effectiveness and efficacy, 5) the relationship between thoughts and emotions, and 6) applications to clinical problems and new types of application. 


\section{Integration with other psychotherapies}

The principles of FAP can enhance other therapies, and FAP has been used in this way with good results. Gaynor and Lawrence (2002) compared Beck's Cognitive Therapy with therapy based on the FAP principles in adolescents with depression. A group of 10 adolescents was divided into two groups depending on the severity of their depression (attempted suicide, medication, etc.). The authors used a protocol consisting of 16 sessions over a period of 8 months followed by 6 months of follow-up. The same therapist was responsible for all interventions. Sessions lasted for 2 hours; techniques commonly used in cognitive therapy were used during the first hour, and a FAP intervention was used during the second hour with in-vivo tasks. Weekly changes were evaluated with several questionnaires and selfreporting inventories. The results showed marked changes in depression-related problems in all participants, which were maintained during follow-up. In general, the percentage change according to several different measures was greater in participants with moderately severe depression than in those with severe depression.

Work underway at the University of Reno (Nevada, USA) combines FAP with Acceptance and Commitment Therapy (ACT) in a type of therapy called Functional-analytic Acceptance and Commitment Therapy (FACT) as part of a program to quit smoking (Callaghan, Gregg, Marx, Kohlenberg, \& Gifford, 2004). To date only the features of this therapy and the population it is aimed at have been described; the data generated by this project are currently being analyzed. This type of integration involving two different therapeutic approaches is not new, as shown in an earlier study by Paul, Mark and Orsillo (1999) of acceptance-based psychotherapy in the treatment of an exhibitionist.

\section{Supervision and improvement of therapeutic skills}

To avoid the pitfalls involved in the use of FAP by inexperienced therapists, some studies have investigated the effect of supervision of therapists to improve their therapeutic skills. Callaghan (2006a) has analyzed the variables that affect the supervision of therapists and the skills a FAP therapist should have.

Some effectiveness and efficacy studies have incorporated therapist supervision and training, although these aspects were not the main topic of research (see, for example, Kohlenberg, Kanter, Bolling, Parker \& Tsai, 2002). One outcome of these studies has been the creation of scales that can be used to evaluate therapeutic skills. An example is the Therapist In-session Strategy Scale (THISS), used to evaluate competence and adherence to therapy. This instrument has been shown to be reliable and useful in therapist training programs (Kohlenberg, Tsai, Parker, Bolling \& Kanter, 1999).

Vandenberghe, Sousa and Oliveira (2005) used FAP strategies to enhance treatment for clients with borderline personality disorder. Six therapists were studied, and each participant was interviewed 4 times over a period of 6 months. Four participants also received supervisory sessions that centered on treating and analyzing the feelings that treatment sessions evoked. Preliminary results of this study indicated that treatment for this type of patient is a painful experience. Findings also suggested that supervision increased the therapist's ability to identify his or her feelings, relate them to the CRB that occurred during sessions and create new strategies for intervention. In summary, supervision was found to improve the use of the client-therapist relationship, and also helped the therapist to cope with the traumatic effects of working with this kind of patient.

Glenn M. Callaghan at the Research Center for Innovative Psychological Assessment and Treatment, San José State University (California, USA) has designed a program called Functional Assessment of Skills for Interpersonal Therapists (FASIT; Callaghan, 2006b). This program offers a way 
to improve therapeutic skills by trying to evaluate and classify the problems a therapist may face during therapy. The program manual provides definitions and examples of problems in areas of interpersonal functioning: assertion of needs, bi-directional communication (providing and receiving feedback), problems with conflict resolution, disclosure skills related to developing interpersonally close relationships, and difficulties with the experience and expression of emotion. Several studies have found this system to be useful (Callaghan, Gregg, et al., 2004; Kohlenberg, Kanter, et al., 2002).

In a randomized controlled trials with 30 clinical graduate psychology students, JoAnne Dahl at Uppsala University in Sweden aimed to study the effect of training in FAP on improvements in the therapeutic alliance. The FAP group received 2 days of training in FAP and a group supervision session, whereas the control group received a short information day about the study and measurements, and the same amount of supervision characterized as reflective listening and supportive therapy. All students met with their clients for 4 sessions in each of the two parts of the study. Clients were student volunteers from other university departments. The dependent variable was the therapeutic alliance, measured with the Working Alliance Inventory Scale. At the time of writing this study was nearing conclusion, and the results are expected soon.

3. New developments in methods for evaluation and data recording

Several ways to obtain data from clinical cases have been used to record and code client-therapist interactions for analysis, and different approaches to the conceptualization of clinical cases have also been tried. One of the most interesting innovations is the Experience of Self Scale (EOSS) used to investigate hypotheses derived from the theory of formation of the self. According to this theory, persons differ in the degree of public versus private stimulus control in the formation of the self, and this may constitute a predictable difference between clinical populations (Kohlenberg, Tsai, Parker, et al., 1999). It has been hypothesized that evaluating the degree of stimulus control may be a useful indicator of strategies for intervention. A study by Kanter, Parker and Kohlenberg (2001) compared EOSS with the Self-Esteem Scale (SES) and the Dissocia tive Experiences Scale (DES) in a group of 284 students and a group of 14 patients with borderline personality disorder. The results indicated that the degree of public stimulus control of their self-experience covaried with self esteem and dissociation. The authors concluded that persons with this type of disorder exert excessive public control on their experience of self.

In another study Glenn Callaghan developed a coding system for client and therapist behaviors called the Functional Analytic Psychotherapy Rating Scale (FAPRS) (Callaghan, Summers \& Weidman, 2003). This system makes it possible to obtain data on the changes that take place during sessions throughout therapy by coding events as in-session problems and improvements (CRB1s and CRB2s), outside problems and outside improvements (OP, OI), client session progression (CRR), therapist response to $\mathrm{CRB}$ (TCRB), therapist missing or otherwise failing to respond to a CRB (MCRB), evoking a CRB (ECRB), or therapist session progression (TPR). One of the advantages of this system is its ability to measure the mechanisms of change proposed by FAP. The application of this system in a case study of a client with personality disorder showed it to be reliable (Callaghan, Summers \& Weidman, 2003). According to the authors, the FAPRS codes can be examined with lag-sequential analysis to determine the relationship between the therapist's and the client's behavior. Moreover, descriptive and basic nonparametric statistics can be used to compare the frequency of problems and improvements during sessions throughout the duration of treatment, in order to determine the effectiveness of therapy in a given clinical case.

Different approaches to case conceptualization have been used in FAP. The first approach, used in efficacy studies (Kohlenberg \& Tsai, 2000; Kohlenberg, Kanter, et al., 2002), represents a way to analyze a case throughout therapy which therapists can use to focus on CRB. This system proposes the conceptualization of cases in the following categories: daily life problems, relevant history, corresponding 
in-session problems (interpersonal/behavioral CRB), corresponding cognitive concepts (cognitive CRB: automatic thought, core beliefs, underlying assumptions), daily life goal, and in-session goal (CRB). This approach helps therapists to synthesize information, clarify their objectives and detect equivalences between what occurs in sessions and outside sessions. Therapists in Spain have used this system in clinical settings to supervise therapists who are not experts in FAP, with excellent results (Valero, Ferro \& López, 2006).

Another way to analyze the client's CRB according to a different type of case conceptualization is the Functional Idiographic Assessment Template (FIAT) system (Callaghan, 2006c). This is an ideographic approach to evaluating types of interpersonal functioning that can be problematic during sessions. The categories on which the FIAT system is based are similar to those of the FASIT program, but refer to the client instead of the therapist: assertion of needs, bi-directional communication, conflict, disclosure and interpersonal closeness, emotional experience and expression. To arrive at a useful conceptualization of a case, the therapist answers a series of questions regarding each category. A study by Callaghan, Summers and Weidman (2003) documented the usefulness of the FIAT system in helping therapists with case conceptualization.

\section{Studies of effectiveness and efficacy}

The effectiveness and efficacy of different therapies have been investigated by groups working at the University of Washington, the University of Wisconsin and San José State University (Bolling, Kohlenberg \& Parker, 2000; Callaghan, Summers \& Weidman, 2003; Kanter, Schildcrout \& Kohlenberg, 2005; Kohlenberg, Kanter, et al., 2002; Kohlenberg, Kanter, Bolling, Wexner, Parker \& Tsai, 2004). The most important clinical trial of FAP published to date (Kohlenberg, Kanter et al., 2002) involved 46 participants divided into two groups: one with 18 participants who received cognitive therapy and one with 28 participants who received FAP-enhanced cognitive therapy (FECT). The study ran for 3 years, and all three therapists who participated in both groups were experts in Beck's Cognitive Therapy. In the cognitive therapy group a standard procedure for Beck's therapy was used, and in the FECT group this therapy was expanded and enhanced to include a broader explanation of the $\mathrm{ABC}$ cognitive paradigm, and the use of client-therapist relationships. Seven specific techniques were used to apply these therapies: setting the scene early through a brief narrative produced by the patient, presenting the expanded rationale and eliciting feedback, using the case conceptualization form, noticing CRB that reflect both problems and improvements, asking questions to evoke CRBs, increasing therapist self-awareness as an aid to detecting and being aware of CRBs, and using the modified thought record of Beck. The results were evaluated with four questionnaires used before and after treatment. In the FECT group improvements were seen in $79 \%$ of the participants, compared to $60 \%$ in the group that received cognitive therapy alone.

A subsequent analysis of these results (Kanter, Schildcrout \& Kohlenberg, 2005) with turn-byturn process-coding of recordings of the therapy sessions examined the therapist's behavior to measure the frequency of in-vivo interventions. The findings indicated that interventions were more frequent by therapists in the FECT group than in the cognitive therapy group, and that this was associated with gains in variables such as closeness, adherence and satisfaction with the therapist. Participants reported greater improvements in their daily life after in-vivo interventions during therapy.

Callaghan, Summers \& Weidman (2003) investigated effectiveness in a case study of a woman with histrionic and narcissistic personality disorder. The clinical sessions were videotaped for later analysis, and the Beck Depression Inventory (BDI) was used before and after treatment. Case conceptualization was based on the FIAT system (Callaghan, 2006c), and the target behaviors identified with this analys is were coded with the FAPRS. Four treatment sessions were taped, analyzed and coded, and the analysis showed statistically significant differences documenting positive changes in the client during therapy. 
Kanter, Landes, Busch, Rusch, Brown, Baruch \& Holman (2006) investigated efficacy in two case studies of clients, one with major depressive disorder and histrionic personality disorder, the other with personality disorder not otherwise specified. A single-subject $A / A+B$ design was used for both clients. In phase A Beck's Cognitive-Behavioral Therapy was used, and in phase B this was complemented with FAP techniques described in the study by Kohlenberg, Kanter and colleagues (2002). At the start of therapy CRBs were identified with the FIAT system (Callaghan 2006c). The clients were asked to record whether or not each CRB occurred during therapy. The therapists reviewed these diary cards weekly to shape the correct reporting of CRBs. The results showed a clear improvement in one client after introduction of the FAP strategies, but no evident change in the other client, who stopped recording CRBs before the end of the study, and whose results immediately before drop-out were in the opposite direction to that expected. As the authors noted, this study needs to be replicated in a larger number of participants and with improved methods.

\section{Experimental studies of the relationship between thoughts and emotions}

As noted above, the relationship between behaviors, thoughts and emotions forms part of FAP. Two experiments have investigated the sequence of automatic thoughts and emotions as a function of the instructions or conceptual explanations provided by the investigators. A study by Kanter, Kohlenberg and Loftus (2002) involved 120 university students divided into two experimental groups. All participants received written information about the cognitive model. One group received information about the $\mathrm{ABC}$ model (where A represents an event or stimulus, B represents cognition and C represents affect), and the other received information about the ACB model. Before and after reading the information all participants performed a computerized image-response task which required them to indicate whether the pictures shown led them to experience thoughts or emotions.

The results indicated that before they read the information, most of the participants in both groups responded to the pictures according to an ABC cognitive model. After they had read the information, however, the number of participants in the ACB group who responded according to the ABC model decreased significantly.

Another study (Kanter, Kohlenberg \& Loftus, 2004) involved 198 university students divided randomly into two groups in which the experimental conditions were similar to those in the study summarized above, but which used images with different arousal levels. Immediately after viewing slides of low-arousal, high-arousal and neutral images, participants were asked to record whether they experienced automatic thoughts first or feelings first. Participants in both groups were given information with information about either the $\mathrm{ABC}$ or the ACB cognitive model. The results were similar to those of the 2002 study by the same authors. Before they were given written instructions, both groups tended to report more thoughts in response to the images. After they had read information about the ABC or ACB models, however, the former group reported more automatic thoughts whereas the latter reported more feelings. The difference was statistically significant within and between groups. There were also signs of a gender difference, with men more likely to be influenced by the ABC model than women. Responses to high-arousal images appeared to be influenced more by the ACB model than the ABC model. One possible conclusion is that participants changed their reactions to the images after receiving instruction. In other words, the type of explanation clients are given about the relationship between thoughts and feelings during therapy appears likely to influence how clients report their own behavior.

\section{Application to clinical problems and new types of application}

Since its inception a variety of clinical applications of FAP have been used for different problems. The FAP manual (Kohlenberg \& Tsai, 1991) gives examples of a number of such applications in patients with different problems. In addition, many published reports have appeared on applications in different 
types of clinical cases. Functional Analytic Psychotherapy has been used successfully for patients with anxiety (Kohlenberg \& Tsai, 1995a; López, Ferro \& Calvillo, 2002) and obsessive-compulsive disorder (Kohlenberg \& Vanderberghe, in press; Vanderberghe, 2007), a case of jealousy (Carrascoso, 2003), clients with depression (Dougher \& Hackbert, 1994; Ferro, Valero \& Vives, 2006; Gaynor \& Lawrence, 2002; Kanter, Landes, et al., 2006; Kohlenberg, Kanter, et al., 2002; Kohlenberg \& Tsai, 1994a) and persons who avoided intimate relationships (Cordova \& Koerner, 1993). It has also been used for patients with personality disorders (Callaghan, Summers \& Weidman, 2003; Koerner, Kohlenberg \& Parker, 1996; Kohlenberg \& Tsai, 1991), specifically borderline personality disorder (Kohlenberg \& Tsai, 2000; Sousa, 2004). It has also been used for marital therapy (Kohlenberg \& Tsai, 1995a; Rabin, Tsai \& Kohlenberg, 1996), and has been applied in clients with sexual problems such as anorgasmia (Oliveira \& Vandenberghe, 2005) and in a case of exhibitionism, together with ACT (Paul, Marx \& Orsillo, 1999). Other successful applications have been reported in individuals who were sexually abused and who were suffering from post-traumatic stress disorder (Kohlenberg \& Tsai, 1998; Prins \& Callaghan, 2002). Other problems that have been treated with FAP include health problems such as chronic pain (Vandenberghe \& Ferro, 2005; Vandenberghe, Ferro \& Furtado, 2003; Vandenberghe, Furtado \& Ferro, 2003) and fibromyalgia (Queiroz \& Vanderberghe, 2006). In children FAP has been used as therapy in a boy with aggressive-defiant behavior (Gosch \& Vandenberghe, 2004).

Other interesting applications have also been reported in other populations. Ongoing work at the University of Chicago involves institutionalized patients with chronic psychosis, major recurrent depression and borderline personality disorder (Holmes, Dykstra, Willians, Diwan \& River, 2003). The program developed for these patients, termed Functional Analytic Rehabilitation (FAR), aims to create an institutional environment that is as life-like as possible. In other words, FAR incorporates many of the social stimuli that occur in reallife situations in order to favor generalization. Therapy proceeds though a hierarchy of progressively more complex and demanding behaviors according to the circumstances of each consumer. This system shapes the focus of both the staff and the consumers. In an environment with functional similarity to real-life settings, both staff and consumers can determine which behaviors are effective in that context. The 2003 article by Holmes and colleagues describes the program and its characteristics, and give examples of problem and target behaviors along with descriptions of cases and how they were managed. However, no effectiveness data have been published to date for FAR.

An important innovation is the use of FAP in group therapy for patients with chronic pain. This research has been led by Luc Vandenberghe at the Catholic University of Goiás in Brazil (Vandenberghe \& Ferro, 2005; Vandenberghe, Ferro \& Furtado, 2003; Vandenberghe, Furtado \& Ferro, 2003). According to these authors, their application of FAP generates interpersonal situations that evoke CRBs related with the problems that arise in persons with chronic pain. A standard therapeutic setting lacks the contingencies that maintain pain in daily life, so the skills acquired in therapy are not generalized to real life situations. When pain occurs outside the therapeutic setting the natural contingencies override the therapist's instructions. The aim is to establish an environment as equivalent as possible to situations in which pain occurs outside therapy, in order to modify the patient's behavior during therapy through reallife interactions. Thus far FAP has been shown effective in several patients who had not obtained relief with other treatments, and published reports provide information on the characteristics of treatment and procedures they have used.

\section{$\underline{\text { Conclusions and future directions }}$}

Here I have attempted to review available publications and studies in progress that deal with the applications and contributions of different psychotherapies. Functional Analytic Psychotherapy is currently being studied from many angles to improve its performance and to integrate it with other therapies, with encouraging results. Research currently in progress is looking into therapist supervision and skill enhancement, and several evaluation systems have been described. Different options are now 
available for data recording and coding to help measure the effectiveness of therapy. Several approaches to explaining the relationship between thought, emotion and behavior have been analyzed, and how these relationships explain clients' behavior has also been studied. New applications of therapy have appeared, as have studies of their efficacy and effectiveness.

One frequent criticism of FAP is the prolonged duration of treatment as presented in the manual and in published clinical cases. As we recently noted (Ferro, Valero \& López, 2007), the duration of therapy is a reflection of the severity of the cases that have appeared in the literature, many of which involved a diagnosis of personality disorder requiring prolonged treatment. Other therapies for this type of disorder (such as the treatment developed by Linehan, 1993) are also lengthy, and in other clinical cases published to date, the duration of FAP is no longer than other types of therapy (see, for example, López, Ferro \& Calvillo, 2002).

The most recent innovations in case conceptualization and therapeutic strategies represent advances with respect to the implementations described in the FAP manual. Studies are still lacking on the efficacy and effectiveness of FAP, although some such studies are now in progress. Coding systems for the therapist's as well as the client's behaviors may make it possible to measure the effects of interventions reliably.

As an earlier analysis of FAP suggested (Fernández \& Ferro, 2006), two aspects that merit additional research seem to stand out: efficacy and integration. Studies of the efficacy of FAP will require solid experimental research designs able to generate quantitative data on the effects of therapeutic interventions. Research on ways to integrate FAP with other types of therapy should continue.

As of this writing, most of the reports of clinical cases in the literature provide no data or are based on examples of client-therapist interactions. The measures used for reporting case studies should be enhanced to include, at the very least, pre- and post-treatment data. Further improvements in the reporting of measures of effectiveness could be achieved by using single-subject evaluations, as noted by Kanter, Landes, and colleagues (2006). Additional studies patterned on the methods used by Callaghan, Summers and Weidman (2003), who solved the measurement problem with a coding system, may also help shed light on the effectiveness of FAP. A further methodological improvement worth investigating is the use of multiple baseline designs across behaviors with intervention for one behavior but not others (which serve as intrasubject controls), and replication in several participants.

Efficacy studies based on reliable group methods will be needed to compare FAP with other therapies known to be effective, with no therapy, and with placebo therapy. If these and other carefullycontrolled and reported studies are carried out, I believe FAP will soon fulfill the criteria for being considered an empirically validated treatment.

\section{$\underline{\text { References }}$}

Bolling, M.Y., Kohlenberg, R. J. \& Parker, C. R. (2000). Behavior Analysis and Depression. In M. J. Dougher (Ed.). Clinical Behavior Analysis. (pp.: 127-152). Reno: Context Press.

Callaghan, G. M. (2006a). Functional Analytic Psychotherapy and Supervision. International Journal of Behavioral and Consultation Therapy, 2, 3, 416-431.

Callaghan, G. M. (2006b). The Functional Assessment of Skills for Interpersonal Therapists: The FASIT System. The Behavior Analyst Today, 7, 399-433. 
Callaghan, G. M. (2006c). The Functional Idiographic Assessment Template (FIAT) System. The Behavior Analyst Today, 7, 357-398.

Callaghan, G. M., Gregg, J. A., Marx, B. P., Kohlenberg, B. S. \& Gifford, E. (2004). FACT: The utility of an integration of Functional Analytic Psychotherapy and Acceptance and Commitment Therapy to alleviate human suffering. Psychotherapy: Theory, Research, Practice, Training, 41, 195-207.

Callaghan, G. M., Summers, C. J. \& Weidman, M. (2003). The Treatment of Histrionic and Narcissistic Personality Disorder Behavior: A single-Subject Demonstration of Clinical Improvement Using Functional Analytic Psychotherapy. Journal of Contemporary Psychotherapy, 33, 4, 321-339.

Carrascoso, F. J. (2003). Jealousy: A case of application of Functional Analytic Psychotherapy. Psychology in Spain, 7, 88-98.

Cordova, J. V. \& Koerner; K. (1993). Persuasion criteria in research and practice: gathering more meaningful psychotherapy data. The Behavior Analyst, 16, 317-330.

Dougher, M. J. \& Hackbert, L. (1994). A behavior-analytic account of depression and a case report using acceptance-based procedures. The Behavior Analyst, 17, 321-334.

Fernandez Parra, A. \& Ferro García, R. (2006). La Psicoterapia Analítico-Funcional una aproximación contextual funcional al tratamiento psicológico. Edupsykhe, 5, 2, 203-229.

Ferro García, R., Valero Aguayo, L. \& López Bermúdez, M. A. (2007). Novedades y aportaciones desde la Psicoterapia Analítica Funcional. Psicothema, 19, 3, 452-458.

Ferro, R., Valero, L. \& Vives, M. C. (2006). Application of Functional Analytic Psychotherapy: Clinical Analysis of a patient with Depressive Disorder. The Behavior Analyst Today, 7, 1-18.

Gaynor, S. T. \& Lawrence, P. S. (2002). Complementing CBT for depressed adolescents with learning through in vivo experience (LIVE): Conceptual Analysis, Treatment description, and feasibility study. Behavioral and Cognitive Psychotherapy, 30, 79-101.

Gosch, C. S. \& Vandenberghe, L. (2004). Behavior analysis and the therapist-child relationship in the treatment of an aggressive-defiant pattern. Revista Brasileira de Terapia Comportamental e Cognitiva, 6, 173-182.

Hayes, S. C. (2004). Acceptance and commitment therapy, relational frame theory, and third wave of behavioral and cognitive therapies. Behavior Therapy, 35, 639-665.

Hayes, S. C., Strosahl, K. D. \& Wilson, K. G. (1999). Acceptance and Commitment Therapy. An Experiential Approach to Behavior Change. New York: The Guilford Press.

Holmes, E. P., Dykstra, T. A., Williams, P., Diwan, S. \& River, L. P. (2003). Functional analytic rehabilitation: A contextual behavioral approach to chronic distress. The Behavior Analyst Today, 4, 34-46.

Kanter, J. W., Kohlenberg, R. J., \& Loftus, E. F. (2002). Demand characteristics, treatment rationales, and cognitive therapy for depression. Prevention \& Treatment, 5, Article 41. 
Kanter, J. W., Kohlenberg, R. J. \& Loftus, E. F. (2004). Experimental and psychotherapeutic demand characteristics and the cognitive therapy rationale: An analogue study. Cognitive Therapy and Research, 28, 2, 229-239.

Kanter, J. W., Landes, S. J., Busch, A. M., Rusch, L. C., Brown, K. R., Baruch, D. E. \& Holman, G. (2006). The Effect of Contingent Reinforcement on Target Variables in Outpatient Psychotherapy for Depression: A Successful and Unsuccessful Case Using Functional Analytic Psychotherapy. Journal of Applied Behavior Analysis, 39, 463-467.

Kanter, J. W., Parker, C. \& Kohlenberg, R. J. (2001). Finding the self: A behavioral measure and its clinical implications. Psychotherapy: Theory, Research and Practice, 38, 198-211.

Kanter, J. W., Schildcrout, J.S., \& Kohlenberg, R. J. (2005). In vivo processes in cognitive therapy for depression: Frequency and benefits. Psychotherapy Research, 15, 4, 366-373.

Koerner, K., Kohlenberg, R. J. \& Parker, R. (1996). Diagnosis of Personality Disorder: A Radical Behavioral alternative. Journal of Consulting and Clinical Psychology, 64, 1169-1176.

Kohlenberg, R. J., Kanter, J. W., Bolling, M.Y., Parker, C. R. \& Tsai, M. (2002). Enhancing Cognitive Therapy for Depression with Functional Analytic Psychotherapy: Treatment Guidelines and Empirical Findings. Cognitive and Behavioral Practice, 9, 213-229.

Kohlenberg, R. J., Kanter, J. W., Bolling, M., Wexner, R., Parker, C. \& Tsai, M. (2004). Functional Analytic Psychotherapy, Cognitive Therapy, and Acceptance. In S. C. Hayes, V. M. Follette \& M. M. Linehan (Eds.). Mindfulness and Acceptance. Expanding the Cognitive-Behavioral Tradition. (pp.: 96-119). New York: Guilford Press.

Kohlenberg, R. J. \& Tsai, M. (1991). Functional Analytic Psychotherapy. Creating intense and curative therapeutic relationship. New York: Plenum Press.

Kohlenberg, R. J. \& Tsai, M. (1994a). Improving cognitive therapy for depression with functional analytic psychotherapy: Theory and case study. The Behavior Analyst, 17, 305-319.

Kohlenberg, R. J. \& Tsai, M. (1994b) Functional Analytic Psychotherapy: A Radical Behavioral Approach to Treatment and Integration. Journal of Psychotherapy Integration, 4, 174-201.

Kohlenberg, R. J. \& Tsai, M. (1995a). Functional analytic psychotherapy: a behavioral approach to intensive treatment. In W. O’Donohue y L. Krasner (Eds.), Theories of behavior therapy. Exploring behavior change, (pp.: 637-658). Washington: APA.

Kohlenberg, R. J. \& Tsai, M. (1995b). I speak, therefore I am: A behavioral approach to understanding the self. The Behavior Therapist, 18, 113-116.

Kohlenberg, R. J. \& Tsai, M.. (1998). Healing interpersonal trauma with the intimacy of the relationship. In V. M. Follette, J. I. Ruzeg y F. R. Abueg (Eds.). Cognitive-Behavioral Therapies for Trauma. (pp.: 305-320). New York: Guilford.

Kohlenberg, R. J. \& Tsai, M.. (2000). Radical Behavioral Help for Katrina. Cognitive and Behavioral Practice, 7, 500-505. 
Kohlenberg, R. J., Tsai, M., Ferro García, R., Valero, L., Fernández Parra, A., \& Virués-Ortega, J. (2005). Psicoterapia analítico-funcional y Terapia de aceptación y compromiso: Teoría, aplicaciones y continuidad con el análisis del comportamiento. International Journal of Clinical and Health Psychology, 5, 2, 37-67.

Kohlenberg, R. J., Tsai, M., Parker, C. R., Bolling, M. Y. \& Kanter, J. W. (1999). Focusing on the ClientTherapist Interaction. Functional Analytic Psychotherapy: A Behavioral Approach. European Psychotherapy, 1, 15-25.

Kohlenberg, R. J. \& Vandenberghe, L. (in press). Treatment resistant OCD, and the therapeutic relationship: Two case examples. The Behavior Therapist.

Linehan, M. M. (1993). Cognitive-Behavioral Treatment of Borderline Personality Disorder. New York: The Guilford Press.

López Bermúdez, M. A., Ferro, R., \& Calvillo, M. (2002). Una aplicación de la Psicoterapia Analítica Funcional en un trastorno de angustia sin agorafobia. Análisis y Modificación de Conducta, 28, 553-583.

Martell, C. R., Addis, M. E. \& Jacobson, N. S. (2001). Depression in context, strategies for guided action. New York: Norton.

O’Donohue, W. (1998). Conditioning and third-generation behavior therapy. In W. O’Donohue (Ed.). Learning and behavior therapy (pp.: 1-14). Needham Heights: Allyn and Bacon.

Oliveira, K. C. F. \& Vandenberghe, L. (2005). Anorgasmia e esquiva experiencial, um estudo de caso. Psicología Clínica, 17, 1, 162-176.

Paul, R. H., Marx, B. P. \& Orsillo, S. M. (1999). Acceptance-based psychotherapy in the treatment of an adjudicated exhibitionist: a case example. Behavior Therapy, 30, 149-162.

Pérez Álvarez, M. (2004). Contingencia y drama. La psicología según el conductismo. Madrid: Minerva Ediciones.

Prins, A. \& Callaghan, G. M. (2002). Functional Analytic Psychotherapy on an adjunctive treatment for a client meeting criteria for PTSD. Poster presented at the 36 Annual Meeting of the Association for the Advancement of Behavior Therapy, Reno, November.

Queiroz, M. A. M., \& Vandenberghe, L. (2006). Psychotherapy in the treatment of fibromialgia: Interweaving FAP and ACT. In H. J. Guilhardi \& N. Aguire. (Eds.). Sobre Comportamento e Cognição. (pp.: 238-248). Santo André: ESETec.

Rabin, C., Tsai, M. \& Kohlenberg, R. J. (1996). Targeting sex-role and power issues with a functional analytic approach: Gender patterns in behavioral marital therapy. Journal of Feminist Family Therapy, 8, 1-24.

Sousa, A. C. A. (2004). Borderline personality disorder from a functional analytic perspective. Revista Brasileira de Terapia Comportamental e Cognitiva, 5, 121-137. 
Valero, L. Ferro, R. \& López, M. A. (2006). El Análisis Funcional desde FAP: La conceptualización de tres casos clínicos. Communication presented at the 8th International Congress on Behavior Studies (CIEC-2006). Santiago de Compostela. Spain.

Vandenberghe, L. (2007). Functional analytic psychotherapy and the treatment of obsessive compulsive disorder. Counselling Psychology Quarterly, 20, 105-114.

Vandenberghe, L., Sousa, A. C. A. \& Oliveira, J. A. (2005). Treating clientes with Borderline Personality Disorder: The impact on the therapist. Communication presented at the 9th European Congress of Psychology. Granada. Spain.

Vandenberghe, L., \& Ferro, C. L. B. (2005). Terapia de grupo baseada em FAP como abordagem terapêutica para dor crônica: Possibilidades e perspectivas. Psicologia: Teoria e prática, 7, 137152.

Vandenberghe, L., Ferro, C. L. B., \& Furtado da Cruz, A. C. (2003). FAP-enhanced group therapy for chronic pain. The Behavior Analyst Today, 4, 369-375.

Vandenberghe, L., Furtado da Cruz, A. C. \& Ferro, C. L. B., (2003). Terapia de grupo para pacientes com dor cronica orofacial. Revista Brasileira de Terapia Comportamental e Cognitiva, 5, 1, 31-40.

Author Note:

I thank K. Shashok for translating the manuscript into English.

Author Contact Information:

Rafael Ferro García

Centro de Psicología Clínica CEDI

Avda. Constitución 25, 7 Izda.

18014 Granada

Spain

E-mail: rferro@cop.es.

Web site: http://www.cop.es/colegiados/GR00777 